\title{
Erratum to: Predictors of Physician Recommendation for Ethically Controversial Medical Procedures: Findings from an Exploratory National Survey of American Muslim Physicians
}

\author{
Sundus Mahdi ${ }^{1}$ - Obadah Ghannam ${ }^{1,2} \cdot$ Sydeaka Watson $^{3} \cdot$ \\ Aasim I. Padela ${ }^{4,5,6,7}$
}

Published online: 19 March 2016

(C) Springer Science+Business Media New York 2016

\section{Erratum to: J Relig Health (2016) 55:403-421 DOI 10.1007/s10943-015-0154-y}

In the original version of the article, Table 3 has been published inadvertently with the incorrect values where frequency data was transposed for the following question items: frequency of seeking guidance from Imams at local mosques when facing bioethics challenge; and frequency of seeking guidance from other Muslim physicians when facing bioethics challenge.

For "frequency of seeking guidance from Imams at local mosques when facing bioethics challenge" readers should be aware that the following are the correct numbers, presented in the following format, no. (\%): Never, 113 (45.4); Rarely, 65 (26.1); Sometimes, 59 (23.7); Often, 12 (4.8).

The online version of the original article can be found under doi:10.1007/s10943-015-0154-y.

\section{Aasim I. Padela}

apadela@medicine.bsd.uchicago.edu

1 The Centre for Islam and Medicine, Cambridge, UK

2 Division of Health Sciences, Warwick Medical School, University of Warwick, Coventry, UK

3 Department of Public Health Sciences, The University of Chicago, Chicago, IL, USA

4 Initiative on Islam and Medicine, Program on Medicine and Religion, The University of Chicago, Chicago, IL, USA

5 Section of Emergency Medicine, Department of Medicine, The University of Chicago, Chicago, IL, USA

6 MacLean Center for Clinical Medical Ethics, The University of Chicago, Chicago, IL, USA

7 The Initiative on Islam and Medicine, Section of Emergency Medicine, 5841 South Maryland Ave., MC 5068, Chicago, IL 60637, USA 
For "frequency of seeking guidance from other Muslim physicians when facing bioethics challenge" readers should be aware that the following are the correct numbers: Never, 52 (21); Rarely, 49 (19.8); Sometimes, 117 (47.2); Often, 30 (12.1).

Within the results section, under subheading "Bioethics Resource Utilization", the second sentence should read: Nearly half (45\%) reported never (instead of often as reported in the original paper) seeking guidance from their local imam when faced with an ethical challenge in medicine $(45 \%)$, and nearly half sometimes sought the counsel of other Muslim physicians (47\%).

This error in no way impacts our discussion section and the implications from findings. 